\title{
Trends in COVID-19 School Related Inquiries Using 311 New York City Open Data
}

\author{
Adriana Eugene $^{1} \cdot$ Naomi Alpert $^{1} \cdot$ Wil Lieberman-Cribbin $^{1} \cdot$ Emanuela Taioli $^{1}$ \\ Accepted: 20 May 2021 / Published online: 26 May 2021 \\ (c) The Author(s), under exclusive licence to Springer Science+Business Media, LLC, part of Springer Nature 2021
}

\begin{abstract}
This study aimed to assess the coronavirus disease (COVID-19) school-related information New York City residents sought through the 311 Call Center. July to November inquiries were downloaded from the NYC Open Data website for 2018-2020. Calls were categorized as related to "Schools", "Access", "Food", "Hospitals", "Transportation", and "Unemployment". Overall call types, and among school-related calls, detailed call types, were compared over the years, using chi-squared tests. School-related inquiries increased by $71 \%$ from 2018 to 2020 . During 2020, the most common $(49 \%, \mathrm{n}=22,471)$ call description was "Coronavirus and Schools", encompassing calls about learning options, safety, and resources. Spikes in these calls corresponded to official announcements, including those about Fall reopening plans (August 31: $\mathrm{n}=678$; September 1: $n=624$ ) and schedules and staffing (September 16th: $n=1043$; September 17th: $n=713$ ), and after the start of in-person learning (September 21: $n=680$ ). This study demonstrates that as government officials updated NYC schooling plans for Fall 2020, there were increased concerns among NYC residents. Future COVID-19 schooling changes need to be conveyed clearly and disseminated effectively in order to avoid confusion about NYC's pandemic learning strategy and to address health and safety concerns.
\end{abstract}

Keywords COVID-19 $\cdot$ Public schools $\cdot$ Information seeking behavior $\cdot$ Informational database $\cdot$ New York City

\section{Introduction}

The novel coronavirus disease (COVID-19), caused by severe acute respiratory syndrome coronavirus 2 (SARSCoV-2), was first observed in Wuhan, China in December, 2019 and was declared a pandemic by the World Health Organization on March 11, 2020 [1]. The primary mechanism of transmission of COVID-19 is contact with respiratory droplets [2] or aerosols from an infected person [3]. In an effort to mitigate the rapid transmission of the virus, the New York State (NYS) governor declared a state of emergency on March 12, 2020 [4], and subsequently banned all large gatherings on March 20, resulting in statewide school and business closures [5]. State officials across the United

Emanuela Taioli

Emanuela.taioli@mountsinai.org

1 Department of Population Health Science and Policy, Institute for Translational Epidemiology, Icahn School of Medicine at Mount Sinai, One Gustave L. Levy Place, Box 1133, New York, NY 10029, USA
States (US) enacted similar orders, resulting in nationwide elementary and high school closures throughout March [6].

Public schools in New York City (NYC) remained closed for in-person learning through the end of the Spring 2020 semester, deferring to remote learning through online platforms. Similar decisions were made in Chicago and Los Angeles [7], the next two largest public school systems in the country. Although these cities all experienced high positive test rates during the first peak of the pandemic in March $2020(\mathrm{NYC}=40 \%$; LA $=40 \%$; Chicago $=21 \%)$ [8], they each followed different reopening paths, based on COVID-19 metrics. Government officials in both LA (Positivity Rate $10 \%$ in July 2020) [8] and Chicago (Positivity Rate 6\% in July 2020) [8] made the proactive decision in July to keep schools closed for in-person learning for the entire Fall 2020 semester [9, 10]. In NYS (Positivity Rate of $1.5 \%$ in July 2020) [8], officials determined students could return to in- person learning, provided that school districts continued to meet the COVID-19 metrics specified by the state health department. Under these guidelines, if COVID19 case counts or positivity rates within a given community exceeded accepted thresholds, those school districts would 
be required to change to remote learning [11]. This decision wasn't made until August, leading to widespread uncertainty, and ultimately translated to a series of openings and partial closings throughout the semester. Challenges included virus transmission, access to remote learning options and technology, childcare options, and access to school meals for food-insecure students. Therefore, NYC presents a unique opportunity to assess the information seeking behaviors of residents in regards to COVID-19 related school re-openings and closures.

The goal of this study was to understand the information seeking behaviors of NYC residents during the phased re-opening of NYC by assessing the frequency of school related, and specifically COVID-19 and school related, calls to NYC's 311 informational service line, from July to November of 2020. 311 has long served as a key resource for NYC residents to access information regarding school calendars and closures, school enrollment, and other necessary NYC school related information [12]. Understanding these patterns may help inform more timely government decisions and improve information dissemination strategies to reduce confusion. As schools diverged in learning plans for the fall semester, we hypothesize that NYC residents utilized the 311 Call Center for school related questions, specifically regarding COVID-19, more than in previous years.

\section{Methods}

The 311 Call Center is a non-emergency service line where residents can submit service requests, file official complaints, and obtain general information on NYC resources and agencies [12]. Language assistance for non-English speakers is available in 6 languages; Spanish, Russian, Cantonese, Mandarin, Korean or Creole. NYC Open Data is a publicly available database that includes all the calls received by the 311 Call Center [12]. This database is updated daily and contains calls from 2010 to the present, along with the date the call was placed, the agency to which the call was directed, the general category of the inquiry, a brief description, and the resolution of each call. Data from the NYC 311 Call Center was directly downloaded from the NYC Open Data website to analyze the frequency and trends of school related calls in NYC.

Calls from July 7-November 22 in 2018, 2019 and 2020 were queried for this analysis. The timeline for analysis was identified based on when NYC entered Phase 3 of its re-opening (July 6, 2020), and when the Mayor announced schools would remain closed for the remainder of the Fall semester (November 18, 2020). When NYC entered Phase 3, school-plans for the fall semester had not yet been announced. [13] Data from the most recent two years were selected to provide a baseline comparison. In order to compare the change in school related calls to other COVID-19 relevant inquiry types, calls were categorized as being related to "Schools", "Access", "Food", "Hospitals", "Transportation", and "Unemployment", based on the presence of those key words in the inquiry name. The key word "School" was specifically excluded when querying the other categories so calls that had already been identified as school-related were not captured twice. A chi-squared test was performed to compare the frequency of each categorized inquiry type across years, relative to the total number of calls received by 311 in the time frame, in order to assess trends over time.

Among the subset of calls that were classified as school related, the frequency of call types, including general school related calls and COVID-19 related school calls were examined by inquiry type and compared over the years. Calls classified as "Coronavirus (COVID-19) and Schools" included those seeking information about learning options, school health and safety, and resources for students during the COVID-19 pandemic. Chi-squared tests were performed to compare the frequency of specific school related inquiries over time, relative to the total number of school related calls, to assess trends from 2018 to 2020, and identify specific areas of greatest concern to residents.

To visualize the impact of major public news announcements on COVID-19 school related calls during the pandemic, call inquiries tagged as "Coronavirus (COVID-19) and Schools" were quantified per day and superimposed with a timeline of COVID-19 related events and official public announcements, collected from publications, major news sources, and the NYS government outlets [11, 14].

\section{Results}

\section{Call Types by Year}

There were $2,421,287$ calls in 2018 (32,836 school related; $1.4 \%) ; 2,017,850$ calls in 2019 (30,626 school related; $1.5 \%)$; and 1,930,251 calls in 2020 (45,602 school related; $2.4 \%)$. There was a statistically significant $(\mathrm{p}<0.01)$ difference over time in the relative frequency of all listed COVID19 related call types, potentially due to the large sample size of calls. From 2018 to 2020 the percent of "School" calls increased by $71 \%$. The percent of "Access" calls, including those related to disability access, Access NYC, and AccessA-Ride, increased by $150 \%$. There was a $500 \%$ increase in the percent of calls seeking information on "Unemployment" and a 200\% increase for "Transportation", which included medical transport and public transportation (MTA) calls. A $5 \%$ decrease in all other types of calls was observed from 2018 to 2020 (Table 1). 
Table 1 Frequency of NYC 311 Call Center Inquiry types from July 7-November 22 during 2018, 2019 and 2020

\begin{tabular}{lllll}
\hline & $2018 \mathrm{n}(\%)$ & $2019 \mathrm{n}(\%)$ & $2020 \mathrm{n}(\%)$ & $\begin{array}{l}\% \text { change } \\
2018- \\
2020\end{array}$ \\
\hline Access & $4798(0.2)$ & $6861(0.3)$ & $8928(0.5)$ & $150 \%$ \\
Food & $28,595(1.2)$ & $30,333(1.5)$ & $62,875(3.3)$ & $175 \%$ \\
Hospital & $8627(0.4)$ & $8381(0.4)$ & $7111(0.4)$ & $3 \%$ \\
School & $32,836(1.4)$ & $30,626(1.5)$ & $45,602(2.4)$ & $71 \%$ \\
Transportation & $6795(0.3)$ & $29,975(1.5)$ & $16,930(0.9)$ & $200 \%$ \\
Unemployment & $1590(0.1)$ & $1923(0.1)$ & $11,236(0.6)$ & $500 \%$ \\
Other & $2,338,046(96.6)$ & $1,909,751(94.6)$ & $1,777,569(92.1)$ & $-5 \%$ \\
Total & $2,421,287$ & $2,017,850$ & $1,930,251$ & $-20 \%$ \\
\hline
\end{tabular}

$n$ number of calls

\section{School-Related 311 Calls}

Changes in the distribution of specific school-related inquiries over time were all statistically significant (all $\mathrm{p}<0.05$ ). From 2018 to 2020 additional specific school related inquiries tags were added to the $311 \mathrm{Call}$ Center database. For example, "Other Ways to Graduate High School" was added as a call inquiry during 2019 and "School Re-opening Complaint" and "Coronavirus (COVID-19) and Schools" were added during 2020 as a result of the COVID-19 pandemic. The total number of school-related inquiries increased by $39 \%$ from 2018 to 2020 . During 2020, the most common $(49 \%, \mathrm{n}=22,471)$ call description was "Coronavirus (COVID-19) and Schools". In prior years, the most common call inquiry during this time period was "School Calendar and Closures" (2018, $\mathrm{n}=8855$ (27.0\%); 2019, $\mathrm{n}=6824(22.3 \%))$. Other common inquiries were "School Finder" (2018, $\mathrm{n}=2530$ (7.7\%); 2019, $\mathrm{n}=1463$ (4.8\%); $2020 \mathrm{n}=1117(2.5 \%)$ ) and "Property Tax AssistanceSchool Tax Relief (STAR)" (2018, $\mathrm{n}=2501$ (7.6\%); 2019, $\mathrm{n}=5854(19.1 \%) ; 2020 \mathrm{n}=3183(7.0 \%))$. From 2018 to 2020 there was an increase in the frequency of "School internet access" inquiries $(2018 \mathrm{n}=2 ; 2020 \mathrm{n}=61)$ (Table 2).

Spikes in the volume of "Coronavirus (COVID-19) and Schools" inquiries corresponded to when announcements about reopening changes were made by state and city public officials (Fig. 1). On August 7, the NYS Governor announced schools would reopen for in-person learning for the Fall 2020 semester; by August 12 the "COVID-19 and Schools" inquiry tag was made available in the 311 Call Center. A spike in these 311 calls occurred between August $31(n=678)$ and September $1(n=624)$. A second

Table 2 Percentage of NYC 311 Call Center Inquiry calls related to Schools from July 7-November 22 during 2018, 2019 and 2020

\begin{tabular}{|c|c|c|c|c|}
\hline Inquiry & $2018 \mathrm{n}(\%)$ & $2019 \mathrm{n}(\%)$ & $2020 \mathrm{n}(\%)$ & p-value \\
\hline Alternative schools and programs & $81(0.3)$ & $33(0.1)$ & $184(0.4)$ & $<0.0001$ \\
\hline Coronavirus (COVID-19) and schools & & & $22,471(49.3)$ & \\
\hline Home instruction and schooling & $167(0.5)$ & $204(0.7)$ & $209(0.5)$ & 0.0004 \\
\hline Other Ways to Graduate High School & & $64(0.2)$ & $40(0.1)$ & $<0.0001$ \\
\hline Property tax assistance-school tax relief (STAR) & $2,501(7.6)$ & $5,854(19.1)$ & $3,183(7.0)$ & $<0.0001$ \\
\hline School calendar and closures & $8,855(27.0)$ & $6,824(22.3)$ & $1,924(4.2)$ & $<0.0001$ \\
\hline School finder & $2,530(7.7)$ & $1,463(4.8)$ & $1,117(2.5)$ & $<0.0001$ \\
\hline School food & $20(0.1)$ & $59(0.2)$ & $85(0.2)$ & $<0.0001$ \\
\hline School health complaint & $293(0.9)$ & $35(0.1)$ & $4(0.01)$ & $<0.0001$ \\
\hline School internet access & $2(0.01)$ & $5(0.02)$ & $61(0.1)$ & $<0.0001$ \\
\hline School reopening complaint & & & $909(2.0)$ & \\
\hline School safety complaint & $412(1.3)$ & $147(0.5)$ & $17(0.04)$ & $<0.0001$ \\
\hline School teaching and learning complaint & $414(1.3)$ & $37(0.1)$ & $53(0.1)$ & $<0.0001$ \\
\hline School transfer & $861(2.6)$ & $884(2.9)$ & $1,320(2.9)$ & 0.0475 \\
\hline Other inquiries & $16,700(50.9)$ & $15,017(49.0)$ & $14,025(31.0)$ & $<0.0001$ \\
\hline Total \# of school related calls & 32,836 & 30,626 & 45,602 & \\
\hline
\end{tabular}

$n$ number of calls 
Fig. 1 Number of "Coronavirus (COVID-19) and Schools" inquiries per day from August 12- November 22, 2020 along with a timeline of major COVID-19 and School related news announcements

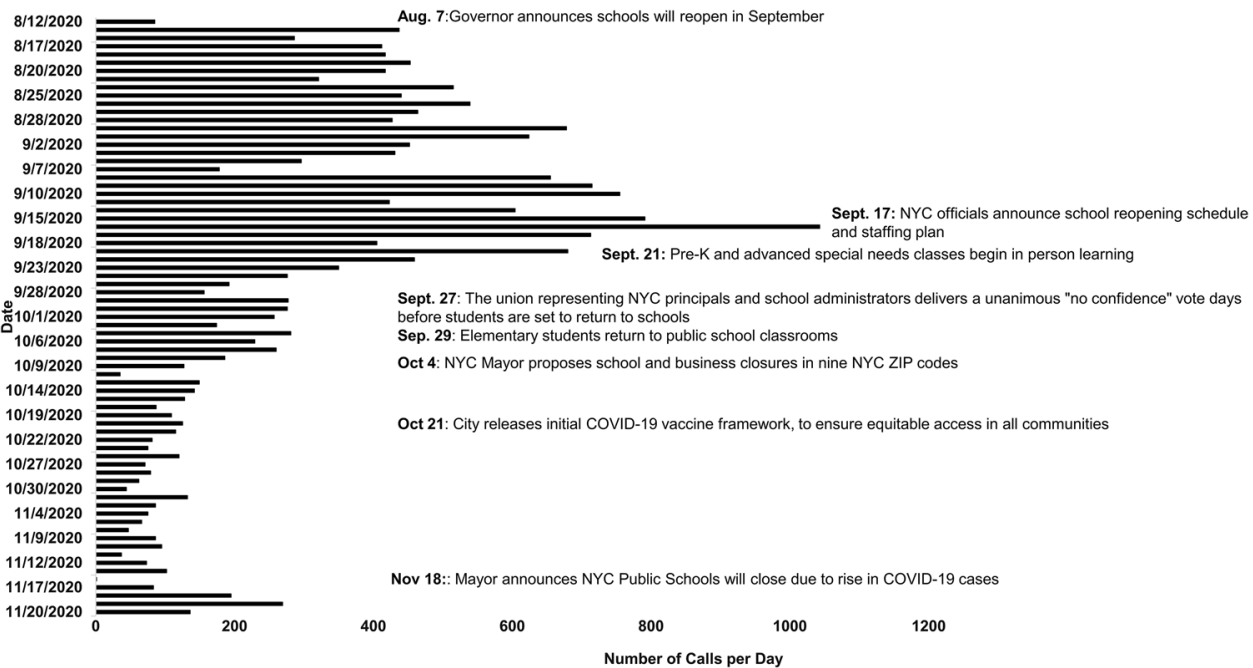

spike occurred between September $16(n=1,043)$ and 17 th $(\mathrm{n}=713)$ when the NYC mayor announced the school reopening schedule and staffing plan, followed by a spike on September $21(\mathrm{n}=680)$ when pre-K and special needs classes began in-person learning. During October, there were no major announcements pertaining to schools; subsequently the volume of calls per day began to decrease. A smaller spike in calls occurred on November $19(n=269)$ when NYC public schools closed for a 2 -week period as a result of the increase in COVID-19 cases.

\section{Discussion}

We show here that the distribution of 311 call types has changed significantly from before the pandemic. The COVID-19 pandemic substantially changed external circumstances, and the relevant concerns and information seeking behaviors of NYC residents have changed as a result. The influx of calls related to unemployment, schools, and food insecurity is not surprising, as the pandemic and corresponding state and local guidelines have left NYC residents with a pronounced level of uncertainty in their lives, particularly around childhood learning and school systems. This study highlights that NYC residents are actively seeking information on learning, school health and safety, and school related resources and tools. From 2018 to 2020 there was an increase in calls seeking information on alternative schools and programs, school internet access, and school food. The increase in these school inquiry types was likely exacerbated by the pandemic, as the guardians of school aged children struggled to adapt to remote learning. Additional challenges may have stemmed from the quick changes to policy and school plans that occurred as COVID-19 metrics fluctuated.

School related calls peaked around major public news announcements related to school closures/openings and policy changes. This suggests that NYC residents actively sought additional or clarifying information on these announcements. NYC schools remained closed from March to June 2020 and uncertainty regarding school format and scheduling for Fall 2020 persisted throughout summer [15]. On August 7 the Governor announced that public schools would be permitted to open in the fall if infection rates were below pre-defined thresholds [16, 17]. However, even after this news announcement it was unclear which NYC school districts would meet the necessary COVID-19 health and safety requirements for in-person learning or partial re-opening.

NYC is unique in that it is the only one of the three largest school districts (NYC, LA and Chicago) to have opted for a more fluid and dynamic decision process, where schools were allowed to open for in-person learning as long as the COVID-19 metrics were below a certain threshold. In order to avoid confusion, government officials and policy makers should make decisions pertaining to school systems and learning options for elementary and high school students in a timely manner. Such decisions must also be communicated clearly in order allow NYC residents time to prepare for any future changes in school schedules. Other major school districts, including Los Angeles and Chicago, decided early to keep schools closed for in-person learning during the Fall 2020 [9, 10], with the hopes of being able to return to in-person learning for Spring 2021. In these cities, school systems and parents had a more stable plan and more time to prepare for remote learning, including acquisition of tablets or computers with access to reliable internet. Additionally, working parents were given more time and warning to make arrangements for childcare. Adequate time to plan for and adjust to these changes is necessary. This would allow parents and school districts to better obtain resources for distance learning and make adjustments to work schedules or caretaker options. 
Another lesson learned from this unexpected situation is the importance of conducting periodic needs assessments among NYC residents to measure the impact of school closures. This could help determine the school districts that require additional resources for learning (e.g. tablets), as well as those that are essential for providing meals to students, thus decreasing parents' confusion and stress regarding schools and the effects of the pandemic.

NYC is a densely and diversely populated area and the disparities in COVID-19 testing, cases, and mortality in lowincome communities within NYC has been well documented [18]. Disparities in these communities extend to alternative learning options and school related resources. Parents or guardians of children living in multi-generational homes, with people at high risk for severe infection [19], may be justifiably reluctant to send their children to school for in person learning [20]. However, many families may lack the technology and resources, including stable internet access and laptops, [21] needed for successful remote learning. School closures may increase food insecurity in children who rely on schools for meals and further economic stress for parents who have to forgo work to provide care at home [22]. Language barriers may also inhibit the ability of parents or guardians to assist children with remote learning. These disparities in COVID-19 school related resources could be one driving force behind the increase in school related calls to the 311 Call Center.

Results presented here should be interpreted within the context of limitations. 311 offers a limited number of language services and therefore, inquiries from NYC residents speaking another primary language may not be captured. It is also possible that NYC residents reached out to specific city agencies directly to request information, bypassing 311 . For example, residents with school related questions could have called the DOE directly. The "COVID-19 and School" tag in 311 may also not capture all pandemic and school related inquiries. For example, it is possible that residents sought information on COVID-19 related school closures and the inquiry was captured under "School closures", instead "COVID-19 and Schools". Therefore, it possible that this analysis undercounts school inquiries directly related to COVID, although the inclusion of these would strengthen our conclusions that NYC residents are actively seeking information in response to the pandemic, especially regarding schools. The 311 database does not contain information regarding the caller's area of residence, therefore, this study was unable to identify specific communities where questions and concerns may be more prominent.

\section{Conclusion}

NYC residents utilized the 311 Call Center to gain information on learning options, school health and safety, and additional resources for students during COVID-19. As a result of the pandemic, residents were seeking information on schools and unemployment at higher rates than in previous years, likely reflecting delayed decisions, changing plans, and subsequent widespread confusion and concern. Information regarding school systems and resources for remote learning need to be communicated to the general public in an accurate and timely manner to avoid such confusion among residents and allow guardians of school-aged children sufficient time to prepare for changes.

Author Contribution Conceptualization of the research: AE, NA, WL-C and ET; data curation: AE; formal analysis: AE and NA; supervision of analysis: ET; writing of manuscript: AE; review and editing of manuscript: NA, WL-C and ET.

Funding No funding was received for conducting this study.

Data Availability 311 Data is available to download at: https:// data.cityofnewyork.us/City-Government/311-Call-Center-Inquiry/ wewp-mm3p.

\section{Declarations}

Conflicts of interest The authors have indicated that they have no potential conflicts of interest to disclose.

Ethical Approval Ethical approval for this type of study is not required by our institute.

\section{References}

1. Cucinotta, D., \& Vanelli, M. (2020). WHO declares COVID-19 a pandemic. Acta Bio-Medica: Atenei Parmensis, 91(1), 157-160. https://doi.org/10.23750/abm.v91i1.9397

2. World Health Orgnaization. (2021). Coronavirus. https://www. who.int/health-topics/coronavirus\#tab=tab_1. Accessed 15 Jan 2021.

3. National Center for Immunization and Respiratory Diseases (NCIRD), Division of Viral Diseases. (2020). How coronavirus spreads. Centers for Disease Control and Prevention. https://www. cdc.gov/coronavirus/2019-ncov/prevent-getting-sick/how-covidspreads.html. Accessed 28 Oct 2020.

4. Mckinley, J., \& Gold, M. (2020, March 12). Ban on large gatherings in N.Y. as coronavirus cases rise sharply. The New York Times. https://www.nytimes.com/2020/03/12/nyregion/coronavirus-nyc-event-ban.html

5. Coronavirus Deaths and Over 5,600 Cases in N.Y.C. (2020, March 20). The New York Times. https://www.nytimes.com/2020/03/20/ nyregion/coronavirus-new-york-update.html?action=click\&module $=$ Spotlight $\&$ pgtype $=$ Homepage\#link-162c31f8. Acessed 15 Jan 2021. 
6. Donohue, J. M., \& Miller, E. (2020). COVID-19 and school closures. JAMA, 324(9), 845-847. https://doi.org/10.1001/jama. 2020.13092

7. Top 10 Largest School Districts by Enrollment and Per Pupil Current Spending. (2019, May). United States Census Bureau.https:// www.census.gov/library/visualizations/2019/comm/largestschool-districts.html. Accessed 1 Feb 2021.

8. U.S. COVID Risk \& Vaccine Tracker. COVID Act Now. https:// covidactnow.org/?s=1583523 Accessed 1 Feb 2021.

9. Los Angeles and San Diego Schools to Go Online-Only in the Fall. (2020, July 13). The New York Times. https://www.nytim es.com/2020/07/13/us/lausd-san-diego-school-reopening.html. Accessed 1 Feb 2021.

10. Reopening Framework. (2020). Chicago Public Schools. https:// www.cps.edu/school-reopening-2020/reopening-framework/ remote-learning-vfgoverview/.. Accessed 1 Feb 2021.

11. The Official Website of Governor Andrew M. Cuomo. https:// www.governor.ny.gov/news. Accessed 22 Nov 2020.

12. Call Center Inquiry. NYC Open Data. https://data.cityofnewy ork.us/City-Government/311-Call-Center-Inquiry/tdd6-3ysr. Accessed 22 Nov 2020.

13. NYC Business. (2020). NYC Business Reopening Guide. https:// www1.nyc.gov/nycbusiness/article/reopening-guide\#phasethree. Accessed 7 Jan 2021.

14. Office of the Mayor I News, Press Releases, Statements and Executive Orders I City of New York. https://www1.nyc.gov/office-ofthe-mayor/news.page. Accessed 22 Nov 2020.

15. Algar, S., \& Fonrouge, G. (2020). When NYC schools could finally reopen and how they could change. New York Post. https:// nypost.com/2020/05/20/will-nyc-schools-be-open-by-the-fall/. Accessed 1 Feb 2021.

16. Governor Cuomo announces that, based on each region's infection rate, schools across New York State are permitted to Open This
Fall. Governor Andrew M. Cuomo. (2020, August 11). https:// www.governor.ny.gov/news/governor-cuomo-announces-basedeach-regions-infection-rate-schools-across-new-york-state-are. Accessed 15 Jan 2021.

17. NYS Department of Health. (2020). Interim guidance for in-person instruction at Pre-K to grade 12 schools during the Covid-19 public health emergency. https://www.governor.ny.gov/sites/defau 1t/files/atoms/files/Pre-K_to_Grade_12_Schools_MasterGuidance. pdf. Accessed 19 Apr 2021.

18. Lieberman-Cribbin, W., Tuminello, S., Flores, R. M., \& Taioli, E. (2020). Disparities in COVID-19 testing and positivity in New York City. American journal of preventive medicine, 59(3), 326332. https://doi.org/10.1016/j.amepre.2020.06.005

19. Centers for Disease Control and Prevention. (2021). People at increased risk and other people who need to take extra precautions. https://www.cdc.gov/coronavirus/2019-ncov/need-extraprecautions/index.html. Accessed 15 Jan 2021.

20. Sharfstein, J. M., \& Morphew, C. C. (2020). The urgency and challenge of opening K-12 schools in the fall of 2020. JAMA, 324(2), 133-134. https://doi.org/10.1001/jama.2020.10175

21. Dorn, E., Hancock, B., Sarakatsannis, J., \& Viruleg, E. (2020). COVID-19 and student learning in the United States: The hurt could last a lifetime. McKinsey \& Company.

22. Sheikh, A., Sheikh, A., Sheikh, Z., \& Dhami, S. (2020). Reopening schools after the COVID-19 lockdown. Journal of Global Health, 10(1), 010376. https://doi.org/10.7189/jogh.10.010376

Publisher's Note Springer Nature remains neutral with regard to jurisdictional claims in published maps and institutional affiliations. 